\title{
Estimation of Particulate Mass and Manganese Exposure Levels among Welders
}

\author{
ANGELA HOBSON ${ }^{1}$, NOAH SEIXAS ${ }^{2} *$, DAVID STERLING ${ }^{3}$ and BRAD \\ A. RACETTE ${ }^{1}$
}

\author{
${ }^{1}$ Department of Neurology, School of Medicine, Washington University, St Louis, MO 63116, USA; \\ ${ }^{2}$ Department of Environmental and Occupational Health Sciences, School of Public Health and \\ Community Medicine, University of Washington, Seattle, WA 98105, USA; ${ }^{3}$ Department of \\ Environmental and Occupational Health, School of Public Health, University of North Texas, Fort
}

Worth, TX 76107, USA

Received 19 May 2010; in final form 3 August 2010; published online 24 September 2010

Background: Welders are frequently exposed to Manganese (Mn), which may increase the risk of neurological impairment. Historical exposure estimates for welding-exposed workers are needed for epidemiological studies evaluating the relationship between welding and neurological or other health outcomes. The objective of this study was to develop and validate a multivariate model to estimate quantitative levels of welding fume exposures based on welding particulate mass and Mn concentrations reported in the published literature.

Methods: Articles that described welding particulate and Mn exposures during field welding activities were identified through a comprehensive literature search. Summary measures of exposure and related determinants such as year of sampling, welding process performed, type of ventilation used, degree of enclosure, base metal, and location of sampling filter were extracted from each article. The natural log of the reported arithmetic mean exposure level was used as the dependent variable in model building, while the independent variables included the exposure determinants. Cross-validation was performed to aid in model selection and to evaluate the generalizability of the models.

Results: A total of 33 particulate and $27 \mathrm{Mn}$ means were included in the regression analysis. The final model explained $76 \%$ of the variability in the mean exposures and included welding process and degree of enclosure as predictors. There was very little change in the explained variability and root mean squared error between the final model and its cross-validation model indicating the final model is robust given the available data.

Conclusions: This model may be improved with more detailed exposure determinants; however, the relatively large amount of variance explained by the final model along with the positive generalizability results of the cross-validation increases the confidence that the estimates derived from this model can be used for estimating welder exposures in absence of individual measurement data.

Keywords: exposure; manganese; welding

\section{INTRODUCTION}

Fume generated during welding processes is a complex mixture of gases, metal oxides, silicates, and fluorides. The generation and composition of weld-

\footnotetext{
*Author to whom correspondence should be addressed. Tel: +1-206-685-7189; fax: +1-206-616-6240;

e-mail: nseixas@u.washington.edu
}

ing fume are dependent on a number of factors that include current and voltage applied (Harris, 2002; Yoon et al., 2003), welding process performed, shielding gas used (if any), type and composition of the fluxes and/or electrodes used, and the type of base metal being welded. Exposure to welding fume is also dependent on work practices (number of welders, posture or position during welding, work speed and 
technique, and use of respirator), the degree of enclosure of the work environment, and the type and effectiveness of mechanical ventilation provided (Stern et al., 1986; Burgess, 1995; Harris, 2002).

Both acute and chronic health effects due to inhalation of welding fume have been well described. For instance, welders have increased frequency, severity, and duration of respiratory tract infections compared to the general population (Howden et al., 1988). Other respiratory complications associated with welding include pulmonary function abnormalities, bronchitis, siderosis, and asthma (Antonini, 2003). Welding fume has been classified as a possible human carcinogen by the International Agency for Research on Cancer (IARC, 1990). Exposure to specific metals in welding fume is also of concern. Iron exposures can lead to siderosis; zinc, copper, and magnesium exposures can cause metal fume fever; and chromium VI can cause severe irritation to the upper respiratory tract and has also been classified as carcinogenic to humans by the IARC (IARC, 1990).

Concerns about exposure to manganese (Mn) have also increased over recent years (Harris et al., 2005; Meeker et al., 2007). Mn, recognized as a neurotoxin since the mid 1800 s, is commonly found in welding fume. Many welders are regularly overexposed to the American Conference of Governmental Industrial Hygienists (ACGIH) threshold limit value (TLV) of $0.2 \mathrm{mg} \mathrm{m}^{-3}$. Two studies in industrial and construction settings estimated that $62 \%$ of welders and $72 \%$ of boilermakers, respectively, were overexposed to the Mn TLV (Korczynski, 2000; Susi et al., 2000). Furthermore, a study that analyzed three distinct welding data sets from the United States Occupational Safety and Health Administration (OSHA), The Welding Institute, and the Center for Construction Research and Training reported mean Mn levels as $0.21,0.26$, and $0.27 \mathrm{mg} \mathrm{m}^{-3}$, respectively (Flynn and Susi, 2010). The ACGIH TLV of $0.2 \mathrm{mg} \mathrm{m}^{-3}$ was primarily set in regard to neurological effects (ACGIH, 1992), and there is a reason to believe that these common overexposures may play a role in the development of parkinsonism.

Multiple case reports and small studies have examined Mn-exposed welders and have described parkinsonism signs, such as tremor (Chandra et al., 1981; Nelson et al., 1993; Discalzi et al., 2000; Racette et al., 2001; Sadek et al., 2003; Koller and Lyons, 2004; Josephs et al., 2005; Bowler et al., 2006a,b, 2007), rigidity (Sadek et al., 2003; Racette et al., 2005; Bowler et al., 2006b), bradykinesia (Sadek et al., 2003; Koller and Lyons, 2004; Racette et al., 2005; Bowler et al., 2006b), and postural instability(Nelson et al., 1993; Discalzi et al., 2000;
Sadek et al., 2003; Koller and Lyons, 2004; Josephs et al., 2005; Racette et al., 2005). Some authors have used the term Mn-induced parkinsonism to describe these neurological changes (Koller and Lyons, 2004; Hernandez et al., 2006). In addition, in one clinical report, parkinsonism in welders was determined to be clinically indistinct from idiopathic Parkinson's disease (PD) with the exception of a younger age at onset for welders (Racette et al., 2001). The authors of a case-control study of $>2$ million death certificates concluded that occupations involving arc welding of steel were associated with PD deaths before age 65 (Park, 2005). However, other epidemiological studies investigating the association between welding and PD have found no clear relationship (Fryzek et al., 2005; Fored et al., 2006).

A limitation of these studies is that occupational exposure assessment has typically been minimal, whereby only current exposures were measured in cross-sectional studies, or job title or 'ever employed' in the industry has been used as the exposure index in the case reports and case-control studies. This type of classification is considered the weakest indicator or approximation of exposure and can introduce a significant amount of exposure misclassification. True exposure-response associations may then be missed. It is recognized that additional scientific evidence is needed to determine the role of welder's exposure to $\mathrm{Mn}$ or other welding fume constituents might play in the development of welding-related parkinsonism or PD. More sophisticated exposure assessment is needed to aid continued epidemiological work.

In studies assessing retrospective exposures, it is ideal to have historical quantified measurements on all study participants. However, in some studies, such detailed information on past exposures may not be available or accessible from workplace records. Estimates of individual exposure must then be made from other available data sources, including self-reported exposure information and exposure values found in the published literature. As part of an ongoing epidemiological study of parkinsonism in welders, the objective of this study was to develop and validate a multivariate model to estimate quantitative levels of welding fume exposures based on welding particulate mass and $\mathrm{Mn}$ concentrations reported in the published literature.

\section{METHODS}

\section{Review of the literature}

A Medline search was performed to identify peerreviewed publications that provide quantitative 
exposure levels among welders in typical work settings, along with descriptive information allowing for appropriate interpretation of the exposures. Keyword search terms, entered singly or in various combinations, included welding, Mn, air monitoring, and occupational exposure. The search included articles from all years through 2009 and included all English language journals. However, articles included for review were restricted to peer-reviewed articles written in English, in which the authors described field welding operations and personal air sampling results. Articles describing studies that used a quasiexperimental design in which results from normal field welding operations were compared to results after introducing supplementary ventilation were also included for review. Experimental studies were excluded for review since conditions are typically more controlled in the experimental setting than during routine field operations and may not reflect true field exposures.

\section{Data extraction and database creation}

Mean levels of particulate mass and $\mathrm{Mn}$ described in each article were extracted from the tables and text and formed the dependent variable for each 'observation' in the data set. Results from studies that included long-term sampling (minimum of $6 \mathrm{~h}$ ) or reported a full-shift time-weighted average (TWA) were included in analysis of the model to increase the likelihood that the measurements were representative of a full-shift exposure. Results from short-term analyses were not included. Information on the welding environment and various welding parameters was extracted and entered into a database. Parameters of interest that could affect or influence exposure levels and comprise the most common exposure determinants regularly reported in the supporting literature included year of sampling (or year of publication when year of sampling was not available), industry, welding process performed, base steel, degree of enclosure, and type of ventilation used. The type of electrode(s) used, other hot work processes that occurred during the sampling period, the sampling filter location, and sampling duration was also noted. A list of these variables along with definitions of each can be found in Table 1.

All concentrations were recorded in milligrams per cubic meter. The number of samples and the summary measures reported, including the arithmetic mean (AM), standard deviation (SD), geometric mean (GM), geometric standard deviation (GSD), and range were also recorded in the database as available.

\section{Statistical analysis}

Model development, validation, and selection. The natural $\log$ of the reported AM particulate or $\mathrm{Mn}$ level was used as the dependent variable in the model, while the independent variables included the exposure determinants, as listed in Table 1, entered as categorical variables. Both particulate mass and $\mathrm{Mn}$ concentrations were entered and a binary independent variable (termed 'Mn_particulate') was created to distinguish between the two analytes. The coefficient for this variable is interpreted as the difference between the $\ln$ Mn concentration and the $\ln$ particulate concentration-or the proportional increase between $\mathrm{Mn}$ and particulate concentrations. When both particulate mass and $\mathrm{Mn}$ concentrations were reported from the same samples, only one outcome was entered. The Mn concentration was used unless a larger number of particulate concentration results were reported for a particular set of samples. All concentrations were considered total particulate or total Mn. In the one case where both total and respirable Mn were provided (Smargiassi et al., 2000), the concentration for total Mn was used in the model for consistency with the other means.

The mean and measures of variance were not reported consistently in the published literature. When the GM and either the GSD or the range were reported, the AM was estimated using the following formulas:

If GM and GSD were reported, AM was estimated by:

$$
\mathrm{AM}=\mathrm{GM} \times\left[\exp \left(0.5 \times\left(\sigma_{\mathrm{L}}^{2}\right)\right],\right.
$$

Where $\sigma_{L}=\ln (\mathrm{GSD})$ (Aitchison and Brown, 1957).

If $\mathrm{GM}$, minimum, and maximum were reported, AM was estimated by:

$$
\mathrm{AM}=\exp \left[\mathrm{u}_{\mathrm{L}}+\left(0.5 \times \mathrm{s}_{\mathrm{L}}\right)\right],
$$

Where $\mathrm{u}_{\mathrm{L}}=(\ln (\min )+\ln (\max )) / 2$

This represents the midpoint of the log-transformed minimum and maximum values to give an estimate of the mean of the log-transformed values.

and Where $\mathrm{s}_{\mathrm{L}}=\ln ($ range $) / 4$.

(This represents an estimate of the SD of the logtransformed values.) (Hein et al., 2008).

Both weighted and non-weighted regression models were developed. Since the means consisted of varying sample sizes, a weighted regression using the inverse of the variance was considered. However, SDs were not commonly reported and estimating the SD from other summary measures resulted in high uncertainty in the SD values. Therefore, similar to 
Table 1. Description of welding particulate and Mn sampling variables available in the published literature that were included as exposure determinants (independent variables) in multivariate regression modeling

\begin{tabular}{ll}
\hline Variable & Description/definition \\
\hline Year & Year of sampling or year of publication if sampling year not provided. \\
& Categories: decades, starting with 2009 and working backward. \\
Industry & Type of industry as described or specified by author(s): \\
& Shipyard: any type of ship building or repair located in a shipyard \\
& Construction: construction activities as indicated by authors \\
& Fabrication: fabrication or maintenance of industrial equipment or workshop welding \\
& Not specified: the type of industry was not specified or results were not stratified by industry when \\
& multiple industries were specified.
\end{tabular}

Welding process $\quad$ Type of welding identified or described by author(s):

SMAW: shielded metal arc welding, manual metal arc welding, stick welding

GMAW: gas metal arc welding, metal inert gas (MIG) welding, metal active gas welding (MAG)

GTAW: gas tungsten arc welding, tungsten inert gas (TIG) welding

FCAW: flux cored arc welding

Not specified: welding process was not specified or results were not stratified by welding process when multiple welding processes were specified.

Enclosure $\quad$ Degree of enclosure where sampling occurred:

Open: space was identified as an open area or large workshop

Enclosed: space was identified as an enclosed space or space was a small room/environment enclosed on three sides

Confined: space was identified as confined or description meet confined criteria (e.g. double bottoms of a ship)

Not specified: space was not specified or could not be determined from description or results were not stratified by enclosure when multiple enclosures were specified

Base metal

As described by authors:

Mild steel: mild or carbon steel

Stainless steel: stainless steel

Both mild and stainless steels: mild and stainless steels were welded together

Not specified: base metal was not specified.

Filter location $\quad$ Where sampling filter was located on study participant:

Inside helmet: filter was placed inside welder protective helmet

Outside helmet: filter was placed outside welder protective helmet, commonly on lapel

Not specified: filter location was not specified.

Hein et al., (2008), the weighted regression was developed using the sample size of each reported mean as the weight.

Model building was completed using several steps. First, a model was fitted to include all available dependent variables. Next, a reduced model was built based on backward stepwise elimination where variables were removed one at a time beginning with the one with the largest $P$-value until all remaining variables were significant. Since the purpose of this analysis was for exposure prediction, rather than hypothesis testing, a $P$-value of 0.1 was chosen for the level of significance. To control for the difference between $\mathrm{Mn}$ and particulate, the variable that distinguished between the two was forced into all models. All two-way interactions of the significant variables were tested before the final model was selected. Finally, since the goal was to develop a stable predictive model that is generalizable, the final reduced model was selected based on the results of cross-validating the model.

A k-fold cross-validation technique was performed whereby, 10 randomly selected, equally sized mutually exclusive subsets of the data were identified. The model was then rerun, excluding each subset once. In each of these 10 trials, natural log mean exposures for the excluded group were predicted using the coefficients of the remaining $90 \%$ of the data. This procedure resulted in one out-ofsample prediction for each observed mean. The out-of-sample predicted values were then regressed on the observed dependent variable values and the $R^{2}$ and root mean squared error (RMSE) from the two models were compared. Pearson's correlation 
coefficients were also computed to evaluate the association between observed and cross-validation predicted exposure levels. All data analysis was performed in Stata 11.0 (StataCorp., College Station, TX, USA).

\section{RESULTS}

The Medline keyword searches resulted in 27 studies that met the established criteria (characterization and measurement results of field, steel welding processes, and published in the English language). One article was excluded because only area samples were reported and two were excluded because mean exposure levels were not reported. An additional article was excluded because it provided only one sample and the representativeness of the work environment of that sample could not be determined. Four additional studies fitting the inclusion criteria that were not identified through Medline were found by their reference in other articles (Korczynski, 2000; Flynn and Susi, 2010). Means from a total of 27 studies were included in the model presented here. A summary of the 27 studies, including specific exposure determinants and summary measures of exposure levels, can be found in the Supplementary Table SI, available at Annals of Occupational Hygiene online. The publication years ranged from 1967 to 2009 . Approximately $85 \%$ of the particulate results were published prior to 1999 , and $70 \%$ of Mn sampling results were published between 2000 and 2009. A total of 60 means, including 33 particulate and $27 \mathrm{Mn}$ means, from these studies were used in the multivariate regression modeling. Five of the included arithmetic Mn means were estimated from their published GM and GSD $(n=2)$ or GM and range $(n=3)$ (See Supplementary Table SI available at Annals of Occupational Hygiene online). A total of 1957 samples, including 996 particulate and $961 \mathrm{Mn}$ samples, were represented in these means. Table 2 includes a summary of the welding particulate and Mn means stratified by the exposure determinants available in the source publications.

Due to the large variation in samples sizes (2-209) represented by the included means, the weighted model gave very little weight to mean levels with smaller sample sizes. Nevertheless, the sample-size weighted and non-weighted models indicated little to no change in parameter estimates or measures of fit so the non-weighted model was selected. Table 3 presents measures of fit and cross-validation results for the model selection process. The full model (Model 1) with all predictor variables explained
$86 \%$ of the variance (adjusted $R^{2}=0.77$ ) in mean $\mathrm{Mn}$ and particulate exposures. The backward stepwise model (Model 2) included the variables that were significant in the full model, which included the Mn_particulate, welding process, enclosure, base, and year. Mn means were not available in the first decade represented in the dataset and were largely not available until the most recent decade; therefore, year was removed from the model. Once year was removed, base metal was no longer significant (model not shown) and was then also dropped from further consideration. Ventilation as a block was not significant in the full or backward stepwise reduced model. However, since the type of ventilation used was expected a priori to influence welding exposures, ventilation was added back into the model (Model 3). All two-way interactions were tested, and there was a significant effect for the interaction between welding process and ventilation (Model 4). To achieve a more parsimonious model, ventilation and the interaction term for welding process and ventilation were removed for a model that included Mn_particulate, welding process, and enclosure (Model 5). Parameter estimates for both models, the one with the interaction term (Model 4) and the more parsimonious model (Model 5), are presented in Table 4.

Although there was some reduction in the $R^{2}$ between the fitted and cross-validated models, the differences in model fit were lowest for Model 5, the reduced model containing $\mathrm{Mn} \_$particulate, welding process, and enclosure. The correlation between observed mean exposures and the cross-validation predicted exposures were high for all models (data not shown) but were highest for Model 5 (Pearson's $r=$ $0.87, P \leq 0.001)$. The variability explained in mean exposures in this model was $76 \%$ (adjusted $R^{2}=$ 0.75). Parameter estimates for this final model are presented in Table 4. The coefficient for Mn_particulate (3.23) indicates that Mn levels constituted 4\% (95\% confidence interval $=2.1-7.2 \%$ ) of total welding particulate mass across studies included in the model $\left(1 / \exp ^{(3.23)}=0.04\right)$. Mean predicted exposures for welding particulate and Mn based on the final model are within a range expected for welders in these conditions (particulate $=0.87-29.96 \mathrm{mg} \mathrm{m}^{-3}$; $\left.\mathrm{Mn}=0.03-1.19 \mathrm{mg} \mathrm{m}^{-3}\right)$.

\section{DISCUSSION}

The objective of this study was to build and validate a multivariate model for estimating exposures for participants in a cohort study examining the relationship between welding and parkinsonism based 
Table 2. Welding particulate and Mn summary measures by exposure determinants available in the published literature

\begin{tabular}{|c|c|c|c|c|c|c|c|c|c|c|}
\hline \multirow[t]{2}{*}{ Variable } & \multicolumn{5}{|c|}{ Particluate $^{\mathrm{a}}$} & \multicolumn{5}{|c|}{ Manganese $^{\mathrm{a}}$} \\
\hline & Means, $n$ & Samples, $n$ & $\begin{array}{l}\text { Mean of } \\
\text { means, (SD) }\end{array}$ & $\begin{array}{l}\text { Range of } \\
\text { means }\end{array}$ & $\begin{array}{l}\text { Range of } \\
\text { concentrations, }(n)\end{array}$ & Means, $n$ & Samples, $n$ & $\begin{array}{l}\text { Mean of } \\
\text { means, }(\mathrm{SD})^{\mathrm{b}}\end{array}$ & $\begin{array}{l}\text { Range of } \\
\text { means }\end{array}$ & $\begin{array}{l}\text { Range of } \\
\text { concentrations, }(n)\end{array}$ \\
\hline \multicolumn{11}{|l|}{ Industry } \\
\hline Fabrication & 13 & 290 & $7.48(10.83)$ & $0.16-37.2$ & $0.05-449.1(13)$ & 12 & 146 & $0.12(0.17)$ & $0.01-0.57$ & $<\operatorname{lod}^{\mathrm{d}}-0.99(8)$ \\
\hline Shipyard & 7 & 324 & $5.32(3.69)$ & $2.70-13.0$ & $0.30-112.0(7)$ & 7 & 361 & $0.46(0.57)$ & $0.06-1.74$ & $0.004-2.67$ (4) \\
\hline Construction & 5 & 204 & $4.86(3.13)$ & $1.72-9.33$ & $1.00-37.30(2)$ & 2 & 16 & $0.09(0.05)$ & $0.06-0.12$ & $0.03-0.30(2)$ \\
\hline Not specified $^{\mathrm{c}}$ & 8 & 178 & $1.65(1.03)$ & $0.63-3.38$ & $0.03-8.67(5)$ & 6 & 438 & $0.37(0.27)$ & $0.05-0.67$ & $0.003-4.93(6)$ \\
\hline \multicolumn{11}{|l|}{ Welding process } \\
\hline SMAW & 9 & 345 & $4.14(2.54)$ & $1.72-9.33$ & $0.30-37.3(6)$ & 15 & 320 & $0.16(0.19)$ & $0.01-0.64$ & $<\operatorname{lod}^{\mathrm{d}}-4.62(9)$ \\
\hline GMAW & 4 & 77 & $2.02(0.87)$ & $1.01-2.90$ & $0.05-12.00(3)$ & 2 & 100 & $0.38(0.17)$ & $0.25-0.50$ & $0.007-4.93$ \\
\hline GTAW & 4 & 106 & $0.72(0.42)$ & $0.16-1.10$ & $0.06-4.10(3)$ & 0 & & & & \\
\hline FCAW & 2 & 16 & $15.23(12.61)$ & $6.31-24.15$ & $1.17-55.46(2)$ & 1 & 29 & 0.05 & & $0.3-0.27$ (1) \\
\hline Not specified ${ }^{c}$ & 14 & 452 & $6.67(9.32)$ & $0.96-37.20$ & $0.30-449.1(13)$ & 9 & 512 & $0.43(0.54)$ & $0.1-1.74$ & $0.002-2.6(8)$ \\
\hline \multicolumn{11}{|l|}{ Base metal } \\
\hline Mild steel & 12 & 338 & $6.28(6.14)$ & $1.10-24.15$ & $0.40-112.0$ & 16 & 473 & $0.29(0.42)$ & $0.01-1.74$ & $0.004-4.93(11)$ \\
\hline Stainless steel & 10 & 308 & $5.12(11.31)$ & $0.16-37.20$ & $0.05-449.10(7)$ & 4 & 144 & $0.10(0.09)$ & $0.01-0.21$ & $<\operatorname{lod}^{\mathrm{d}}-0.80$ \\
\hline Mild and stainless & 4 & 272 & $4.58(1.28)$ & $3.00-5.80$ & $0.10-37.30(4)$ & 3 & 177 & $0.31(0.29)$ & $0.05-0.64$ & $0.003-4.60$ \\
\hline Not specified ${ }^{c}$ & 5 & 78 & $4.43(4.89)$ & $0.63-13.00$ & $0.03-70.20(4)$ & 4 & 167 & $0.27(0.47)$ & $0.01-067$ & $0.002-1.56(2)$ \\
\hline \multicolumn{11}{|l|}{ Enclosure } \\
\hline Confined & 6 & 236 & $12.52(12.43)$ & $4.90-37.20$ & $0.30-449.1(6)$ & 3 & 64 & $0.76(0.85)$ & $0.21-1.74$ & $0.01-2.60(2)$ \\
\hline Enclosed & 4 & 121 & $4.38(3.32)$ & $2.30-9.33$ & $0.70-77.80(4)$ & 3 & 24 & $0.26(0.27)$ & $0.1-0.57$ & $0.01-0.80(3)$ \\
\hline Open & 16 & 349 & $3.85(5.61)$ & $0.16-24.15$ & $0.03-74.40(16)$ & 15 & 375 & $0.13(0.17)$ & $0.01-0.64$ & $<\operatorname{lod}^{\mathrm{d}}-4.60(10)$ \\
\hline Not specified ${ }^{\mathrm{c}}$ & 7 & 290 & $2.56(2.14)$ & $0.96-5.80$ & $1.0-37.30(1)$ & 6 & 498 & $0.35(0.57)$ & $0.01-0.67$ & $0.002-4.93(5)$ \\
\hline \multicolumn{11}{|l|}{ Ventilation } \\
\hline None & 13 & 401 & $3.64(1.59)$ & $0.63-6.70$ & $0.30-112.00(12)$ & 8 & 121 & $0.39(0.57)$ & $0.02-1.74$ & $0.01-2.6(6)$ \\
\hline General & 8 & 114 & $8.94(13.89)$ & $0.16-37.20$ & $0.05-449.10(7)$ & 7 & 355 & $0.18(0.17)$ & $0.01-0.50$ & $<\operatorname{lod}^{\mathrm{d}}-4.93(4)$ \\
\hline Local & 4 & 116 & $3.30(2.05)$ & $1.99-6.31$ & $0.50-55.46(3)$ & 5 & 61 & $0.06(0.07))$ & $0.01-0.18$ & $0.005-0.37$ (3) \\
\hline Not specified ${ }^{\mathrm{c}}$ & 8 & 365 & $5.01(4.71)$ & $0.96-13.00$ & $0.20-88.30(5)$ & 7 & 424 & $0.34(0.26)$ & $0.01-0.67$ & $0.002-4.6(7)$ \\
\hline \multicolumn{11}{|l|}{ Filter Location } \\
\hline Outside weld helmet & 8 & 240 & $9.34(11.98)$ & $1.10-37.20$ & $0.05-449.10(7)$ & 10 & 108 & $0.08(0.11)$ & $0.01-0.33$ & $<\operatorname{lod}^{\mathrm{d}}-0.46(4)$ \\
\hline Inside weld helmet & 7 & 126 & $1.73(1.08)$ & $0.63-3.38$ & $0.05-449.1(6)$ & 8 & 510 & $0.24(0.19)$ & $0.05-0.64$ & $0.003-4.6(7)$ \\
\hline Not specified ${ }^{\mathrm{c}}$ & 17 & 627 & $3.60(2.11)$ & $0.16-7.90$ & $0.06-112.0(14)$ & 9 & 343 & $0.48(0.52)$ & $0.03-1.74$ & $0.004-0.4 .93(9)$ \\
\hline
\end{tabular}




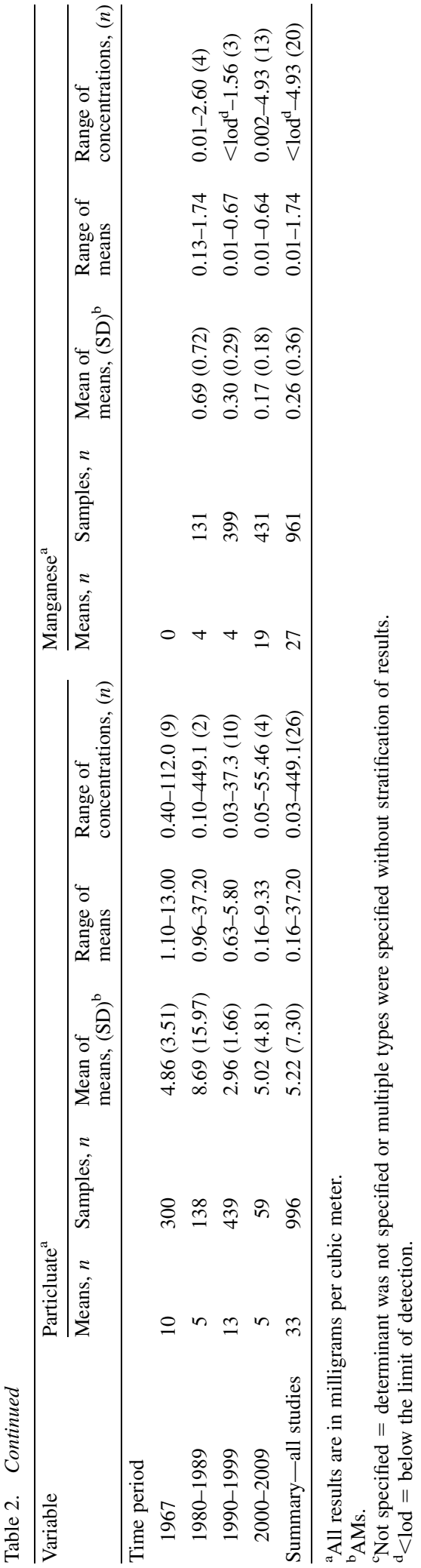

on exposure levels described in the peer-reviewed literature. The approach presented here is a novel method for estimating both welding particulate and Mn mean exposures through the use of one prediction model. Nearly 30 articles described welding environments and provided field measurements on welding fume exposures, including $\mathrm{Mn}$. On the basis of this data, a general model was constructed that describes and predicts exposures. The model performs well at predicting mean welding exposures given the available data, though individual circumstances may deviate from these general conditions, and the specificity with which the welding environments were described in the literature cannot be guaranteed. This lack of specificity is a limitation of the presented model; however, in the context of epidemiology where no individual or site-specific measurements are available, this model should be useful in providing quantitative estimates of welding particulate mass or $\mathrm{Mn}$ in a variety of work settings. For example, if a welder is known to perform gas metal arc welding (GMAW) [or metal inert gas (MIG) or metal active gas welding (MAG)] in an enclosed space, we can take the parameter estimates from Model 5 in Table 4 to estimate a mean particulate and $\mathrm{Mn}$ exposures using the following equations:

$$
\begin{aligned}
& \text { Mean particulate }\left(\mathrm{mg} \mathrm{m}^{-3}\right) \\
& \begin{array}{r}
=\exp ^{\left[-2.72+3.23\left(\mathrm{Mn}_{-} \text {particulate }\right)\right.} \\
+0.45(\mathrm{GMAW})-1.20(\mathrm{GTAW})
\end{array} \\
& +1.24(\text { FCAW })+0.23 \text { (weld not specified) } \\
& +0.78 \text { (enclosed space) } \\
& +1.65 \text { (confined space) } \\
& +0.55 \text { (enclosure not specified)], } \quad 1.1
\end{aligned}
$$

Where $-2.72=$ Y intercept, Mn_particulate $=1$, GMAW $=1$, gas tungsten arc welding $($ GTAW $)=$ 0 , flux cored arc welding $($ FCAW $)=0$, Weld not specified $=0$, enclosed space $=1$, confined space $=0$, and enclosure not specified $=0$.

The equation is exponentiated since the observed means were natural $\log$ transformed. Therefore, mean particulate in this scenario $=5.7 \mathrm{mg} \mathrm{m}^{-3}$.

$$
\begin{aligned}
\text { Mean } \operatorname{Mn} & \left(\mathrm{mg} \mathrm{m}^{-3}\right) \\
=\exp ^{[} & -2.72+3.23\left(\mathrm{Mn}_{-} \text {particulate }\right) \\
& +0.45(\mathrm{GMAW})-1.20(\text { GTAW }) \\
& +1.24(\text { FCAW })+0.23 \text { (weld not specified }) \\
& +0.78(\text { enclosed space }) \\
& +1.65(\text { confined space }) \\
& +0.55(\text { enclosure not specified })],
\end{aligned}
$$

Where all equation (1.1) values hold true except Mn_particulate $=0$. 
Table 3. Exploratory and cross-validation models of natural log-transformed welding particulate and Mn levels: model selection process and measures of fit

\begin{tabular}{|c|c|c|c|c|}
\hline \multirow[t]{2}{*}{ Model and model selection process } & \multicolumn{4}{|l|}{ Measures of fit $^{\mathrm{a}}$} \\
\hline & & $R^{2}$ & Adjusted $R^{2}$ & RMSE \\
\hline $\begin{array}{l}\text { 1: Mn_particulate }{ }^{\mathrm{b}} \text {, industry, welding process, } \\
\text { enclosure, ventilation, base, year, filter location (full) }\end{array}$ & Model & 0.86 & 0.77 & 0.99 \\
\hline All variables were entered to begin model building. & Cross-validation & $\mathrm{n} / \mathrm{a}$ & $\mathrm{n} / \mathrm{a}$ & $\mathrm{n} / \mathrm{a}$ \\
\hline \multicolumn{5}{|l|}{$\begin{array}{l}\text { Weld type, enclosure, base, and year were all } \\
\text { significant blocks. }\end{array}$} \\
\hline $\begin{array}{l}\text { 2: Mn_particulate }{ }^{\mathrm{b}} \text {, welding process, enclosure, year, } \\
\text { base (backward stepwise) }\end{array}$ & Model & 0.81 & 0.75 & 1.03 \\
\hline $\begin{array}{l}\text { Backward stepwise selection was performed to reduce } \\
\text { the model. }\end{array}$ & Cross-validation & 0.63 & 0.63 & 1.26 \\
\hline \multicolumn{5}{|l|}{$\begin{array}{l}\text { Year as a block was significant, but particulate means } \\
\text { were overrepresented and Mn means were } \\
\text { underrepresented in earlier time periods. Year was } \\
\text { excluded from further model building. Base was also } \\
\text { removed from further model building because it was no } \\
\text { longer significant after year was removed. }\end{array}$} \\
\hline $\begin{array}{l}\text { 3: Mn_particulate }{ }^{\mathrm{b}} \text {, welding process, enclosure, } \\
\text { ventilation }\end{array}$ & Model & 0.78 & 0.73 & 1.08 \\
\hline $\begin{array}{l}\text { Ventilation was added to the model because the trend } \\
\text { for general and local ventilation were in the expected } \\
\text { direction (lower than no mechanical ventilation, local } \\
\text { lower than general). }\end{array}$ & Cross-validation & 0.66 & 0.65 & 1.21 \\
\hline $\begin{array}{l}\text { 4: Mn_particulate }{ }^{\mathrm{b}} \text {, welding process, enclosure, } \\
\text { ventilation, weld type } \times \text { ventilation }\end{array}$ & Model & 0.85 & 0.77 & 0.99 \\
\hline $\begin{array}{l}\text { All interactions were tested and added to the model if } \\
\text { significant. }\end{array}$ & Cross-validation & 0.60 & 0.59 & 1.32 \\
\hline $\begin{array}{l}\text { 5: Mn_particulate }{ }^{\mathrm{b}} \text {, welding process, enclosure (final } \\
\text { reduced model) }\end{array}$ & Model & 0.76 & 0.73 & 1.08 \\
\hline $\begin{array}{l}\text { Forward stepwise selection was performed to reduce } \\
\text { the model. After additional model building and cross- } \\
\text { validation was performed, this became the final reduced } \\
\text { model. }\end{array}$ & Cross-validation & 0.75 & 0.75 & 1.04 \\
\hline
\end{tabular}

${ }^{\text {a } M e a s u r e s ~ o f ~ f i t: ~} R^{2}=$ multiple coefficient of determination, adjusted $R^{2}=$ multiple coefficient of determination adjusted for number of indpendent variables, and RMSE = square root of the variance of the residuals/SD of the unexplained variance. ${ }^{\mathrm{b}} \mathrm{Mn} \_$particulate $=$the binary variable that differentiates between manganese or particulate mass, coded as manganese $=0$, and particulate mass $=1$.

Therefore, mean $\mathrm{Mn}$ in this scenario $=0.23$ $\mathrm{mg} \mathrm{m}^{-3}$. More detailed uses of this model could occur when information about a welder's duties are known. For example, fractions of the calculated exposures could be combined when the percent of work time performing various welding processes in various degrees of enclosure is known.

Given that this approach relied on exposure levels reported in the literature, it was subject to a number of limitations. First, not all studies reported an $\mathrm{AM}$, and thus, the AM was estimated from the GM and GSD where necessary. While this introduces some uncertainty in the estimated AM, it should not have had a large effect on the model since this is a valid method of estimating the AM and the estimated AM's consisted of $<10 \%(n=5)$ of the overall data.
Second, when modeling a mean based on varying sample sizes, the literature supports a method of weighting the means proportional to the inverse of their variances (Hornung et al., 1994). However, measures of variance were not reported consistently in the literature, and the SDs were not commonly included. An attempt to estimate the SD where necessary from either the range or the GM and GSD were made; however, this could not be done for several means due to the lack of reported corresponding measures of variance. Since multiple methods were used to estimate the SD, there was a high degree of uncertainty in the estimated values. Therefore, as to not restrict the amount of data available and to avoid this additional source of uncertainty, the sample size was used. Since the sample sizes varied in magnitude (2-209), the weighted model discounted 
Table 4. Regression estimates for two reduced models of welding determinants on mean welding particulate and manganese levels

\begin{tabular}{|c|c|c|c|c|c|c|}
\hline \multirow[t]{2}{*}{ Variable } & \multicolumn{3}{|c|}{ Model 4} & \multicolumn{3}{|c|}{ Model $5^{\mathrm{a}}$} \\
\hline & $\bar{\beta}$ & SE & $95 \% \mathrm{CI}$ & $\bar{\beta}$ & SE & $95 \% \mathrm{CI}$ \\
\hline Constant & -2.52 & 0.41 & -3.35 to -1.68 & -2.72 & 0.28 & -3.28 to -2.16 \\
\hline Mn_particulate ${ }^{\mathrm{b}}$ & 3.04 & 0.3 & 2.42 to 3.65 & 3.23 & 0.30 & 2.62 to 3.83 \\
\hline \multicolumn{7}{|l|}{ Welding process } \\
\hline SMAW & Ref & Ref & $\mathrm{n} / \mathrm{a}$ & Ref & Ref & $\mathrm{n} / \mathrm{a}$ \\
\hline GMAW & 0.42 & 1.07 & 1.75 to 2.59 & 0.45 & 0.51 & -0.56 to 1.47 \\
\hline GTAW & -0.98 & 1.07 & -3.15 to 1.19 & -1.20 & 0.62 & -2.45 to 0.048 \\
\hline FCAW & -1.88 & 1.12 & -4.16 to 0.39 & 1.24 & 0.68 & -0.13 to 2.62 \\
\hline Not specified & 0.54 & 0.47 & -0.42 to 1.49 & 0.23 & 0.34 & -0.45 to 0.90 \\
\hline \multicolumn{7}{|l|}{ Enclosure } \\
\hline Open & Ref & Ref & $\mathrm{n} / \mathrm{a}$ & Ref & Ref & $\mathrm{n} / \mathrm{a}$ \\
\hline Enclosed & 0.32 & 0.46 & -0.61 to 1.26 & 0.78 & 0.47 & -0.17 to 1.73 \\
\hline Confined & 1.53 & 0.43 & 0.65 to 2.41 & 1.65 & 0.45 & 0.75 to 2.55 \\
\hline Not specified & 0.25 & 0.39 & -0.55 to 1.05 & 0.55 & 0.36 & -0.18 to 1.28 \\
\hline \multicolumn{7}{|l|}{ Ventilation } \\
\hline None & Ref & Ref & $\mathrm{n} / \mathrm{a}$ & & & \\
\hline General & -0.31 & 0.55 & -1.42 to 0.82 & & & \\
\hline Local & -0.98 & 0.58 & -2.16 to 0.19 & & & \\
\hline Not specified & 1.41 & 0.59 & 0.21 to 2.61 & & & \\
\hline \multicolumn{7}{|c|}{ Welding process $\times$ ventilation } \\
\hline GMAW $\times$ general & 0.65 & 1.34 & -2.1 to 3.38 & & & \\
\hline GMAW $\times$ local & 1.11 & 1.51 & -1.96 to 4.17 & & & \\
\hline $\mathrm{GMAW} \times \mathrm{NS}^{\mathrm{c}}$ & -1.64 & 1.34 & -4.36 to 1.07 & & & \\
\hline GTAW $\times$ general & -1.06 & 1.5 & -4.11 to 1.98 & & & \\
\hline GTAW $\times$ local & $\mathrm{n} / \mathrm{a}$ & $\mathrm{n} / \mathrm{a}$ & $\mathrm{n} / \mathrm{a}$ & & & \\
\hline GTAW $\times \mathrm{NS}^{\mathrm{c}}$ & -1.03 & 1.33 & -3.74 to 1.67 & & & \\
\hline FCAW $\times$ general & 4.85 & 1.58 & 1.66 to 8.05 & & & \\
\hline FCAW × local & 4.19 & 1.57 & 1.01 to 7.38 & & & \\
\hline $\mathrm{FCAW} \times \mathrm{NS}^{\mathrm{c}}$ & $\mathrm{n} / \mathrm{a}$ & $\mathrm{n} / \mathrm{a}$ & $\mathrm{n} / \mathrm{a}$ & & & \\
\hline $\mathrm{NS} \times$ general $^{\mathrm{c}}$ & 0.19 & 0.78 & -1.39 to 1.77 & & & \\
\hline $\mathrm{NS} \times$ local $^{\mathrm{c}}$ & 0.35 & 0.96 & -1.60 to 2.31 & & & \\
\hline $\mathrm{NS} \times \mathrm{NS}^{\mathrm{c}}$ & -2.09 & 0.78 & -3.68 to -0.51 & & & \\
\hline $\mathrm{N}$ & 60 & & & 60 & & \\
\hline $\mathrm{F}$ & 10.45 & & & 20.49 & & \\
\hline$R^{2}$ & 0.85 & & & 0.76 & & \\
\hline Adjusted $R^{2}$ & 0.77 & & & 0.73 & & \\
\hline RMSE & 0.99 & & & 1.08 & & \\
\hline
\end{tabular}

CI, confidence interval.

${ }^{\mathrm{a}}$ Final reduced model based on cross-validation results.

${ }^{\mathrm{b}} \mathrm{Mn} \_$particulate $=$the binary variable that differentiates between manganese or particulate mass, coded as manganese $=0$ and particulate mass $=1$.

${ }^{\mathrm{c}} \mathrm{NS}=$ ventilation or welding process was not specified.

the small $\mathrm{n}$ means substantially. Even so, the results from the weighted and non-weighted model were very similar and thus, the results from the nonweighted model are reported.
Finally, the studied welding environments and processes were not well described in multiple articles resulting in missing exposure determinant information. The type of electrodes used was rarely 
reported in the published literature, and when they were, the results were not always stratified by the electrode type. A larger portion of welding fume can be generated from the flux on welding electrodes than from the base metal itself, while the metal content in electrodes can vary substantially by type. Type of electrode could not be included in the model due to lack of information, and this prediction model may have different results if electrode type were included. Additionally, several studies sampled multiple welding activities located in varying work environments without stratifying the results. For instance, authors may have sampled exposures from shielded metal arc welding (SMAW) and GMAW processes and/or from confined and open spaces, but the monitoring results were presented as a combined measure. The results could not be associated with one determinant or another; therefore, the exposure determinants were given the classification of 'not specified'. In typical linear regression models, cases with such missing independent variables would be excluded from analysis. However, as to not severely restrict the data, a category of not specified was included for all independent variables. The coefficients for the 'not specified' categories should be interpreted with caution since no distinct exposure information can be attributed to them. With more detailed information on the welding processes and work environments, this model may be improved.

There was a trend for time period, with slightly lower exposures in later time periods, in the full model; however, there may have been a publication year bias since $70 \%$ of Mn means were published in the most recent time period (2000-2009). Due to this uncertainty, year was excluded from the model. The highest mean Mn exposure $\left(1.74 \mathrm{mg} \mathrm{m}^{-3}\right)$ from the studies included in the model was from a study performed in 1981 (Chandra et al., 1981). A plot of the means (not shown) indicated that except for this highest Mn mean, there was no significant trend in Mn exposures over time. Similarly, Flynn and Susi (2010) demonstrated that Mn personal exposures from 1978-2008 in a database of OSHA welding measurements had a 'fairly stable mean from 1984 until 2008; however, there is some indication of higher exposures in earlier years' (p.123). It is possible that Mn exposures were higher in earlier time periods, but with an absence of prior $\mathrm{Mn}$ data for inclusion in the model, this could not be determined. The model indicates that overall $\mathrm{Mn}$ accounts for $\sim 4 \%$ of particulate mass. If welding particulate is known for time periods when Mn was not monitored, a rough estimate of Mn would be $4 \%$ of the particulate concentration.
Base metal was not significant after year was excluded. The base steel generally has a smaller role in fume generation relative to the type/composition of the electrode used (Howden et al., 1988; Antonini, 2003) so it too was excluded from the model. The type of industry in which these welding activities were located was not a significant predictor, indicating that there are no industry-specific differences in welding exposures and that the variability in the task-specific determinants are more important than the overarching industry.

In contrast to a priori expectations, ventilation alone was also not a significant predictor of mean exposures across studies. There appears to be a trend in mean Mn exposures based on ventilation category (Table 3) where mean exposures with general ventilation were about half of those with no mechanical ventilation and the lowest exposures occurred with the use of local ventilation. However, this trend is not apparent with mean particulate exposures. Although not common, several studies reported the presence of other hot work and/or work activities occurring in the work environments where welding exposures were monitored. The presence of these activities may be partly responsible for the higher particulate exposures. A 2007 evaluated the effectiveness of local exhaust ventilation during SMAW installation of carbon steel chiller pipes and found that local exhaust ventilation reduced fullshift TWA Mn concentrations by 53\% but reduced total particulate exposures only by $10 \%$. They concluded that the presence of other sources of particulate generation in construction settings may be responsible for the lower reduction in particulate exposures than for specific fume constituents like Mn (Meeker et al., 2007). In addition, in Model 4, there was a significant interaction for ventilation and welding process, which indicated that local ventilation may be effective at reducing exposures. Although exposures may still be high given the welding process performed. For instance, exposures from FCAW, which produces large quantities of particulate (Burgess, 1995; Wallace et al., 2001; Harris, 2002), with local ventilation were higher than mean exposures for other welding processes when general or no ventilation was used. While application of effective local exhaust ventilation will certainly reduce exposures where other conditions remain the same, we were unable to estimate this effect from the available literature values. In general, estimated exposures ignoring ventilation parameters are likely valid, while acknowledging the importance of using ventilation for effective exposure control. 
An interaction between type of enclosure and ventilation used was tested but was not significant. In a recently published study by Flynn and Susi (2010), the effect of ventilation on welding exposures was evaluated in two welding data sets with mixed results. Particulate and Mn exposures were reduced by 35 and $31 \%$, respectively, with local exhaust ventilation in a Welding Institute data set. Data from another welding database showed that mechanical exhaust (general and/or local) was effective at reducing exposures for pipefitters, but exposures increased for boilermakers working in confined spaces when general ventilation (blowers and fans) was added. This further illustrates that the type of ventilation alone may not be useful in predicting mean exposures and consideration of other important determinants such as degree of enclosure and welding process is important when assessing the effectiveness of different types of ventilation.

To evaluate whether a prediction could be made for exposure levels inside and outside a welding helmet, the location of the sampling filter was included in the full model; however, it was not a significant predictor of mean exposures across studies. As presented in Table 2, mean exposures for particulate were higher outside of the helmet than inside. Conversely, mean Mn exposures were higher inside the helmet. Similarly, Flynn and Susi (2010) also performed an analysis of unpaired filter location results and found that TWA exposures for welding particulate were $50 \%$ lower when the filter was inside the helmet and that TWA exposures for Mn were unchanged by filter location. These results imply that across these studies, the location of the sampling filter was not significant in estimating exposures. It does not imply differences in individual or mean exposures will not be detected when a paired analysis with a filter inside and outside the helmet is performed. Other experimental studies designed to evaluate the differences inside and outside the helmet have reported mixed results (Goller and Paik, 1985; Liu et al., 1995; Harris et al., 2005; Boelter et al., 2009). Studies that compare exposures from paired samples inside and outside the welder helmet during typical field operations may be needed to evaluate these factors.

Welding process and degree of enclosure were both significant predictors of mean exposure levels. There was little difference between SMAW (reference category) and predicted GMAW exposures, but predicted GTAW exposures were much lower and predicted FCAW exposures were generally much higher. This is consistent with published sources of welding process and fume descriptions (Wallace et al., 2001; Harris, 2002). As expected, predicted exposures in enclosed spaces were higher than exposures in open spaces (reference category), and predictions for exposures in confined spaces were significantly higher than in open spaces.

Cross-validation of all reduced models was performed to evaluate model fit and generalizability of the model. The method used, k-fold cross-validation, was chosen because it performs significantly better for validation of small data sets, such as the one used for this study, than other methods such as split-sample validation (Goutte, 1997). Model 4, the model containing an interaction term for enclosure and ventilation that explained $85 \%$ of the variance in mean welding particulate and Mn exposures, could be used for prediction purposes if this detail on exposure determinants is known for a study group. However, comparison of the differences in measures of fit $\left(R^{2}\right.$, Adjusted $R^{2}$, and RMSE) for the reduced models along with their respective cross-validation models determined that the reduced model with fewer independent variables (i.e. more parsimonious) had the smallest changes. The other reduced models had drops in $R^{2}$ values between 12 and $25 \%$, whereas, the $R^{2}$ values for the final model (Model 5) were virtually unchanged. This indicates that the final model fits the data better than the other reduced models with additional predictors. The very small change in $R^{2}$ and the similar RMSE values for the final model indicates that the model should be generalizable to other data sets of mean welding particulate and $\mathrm{Mn}$ exposures. The correlation between observed means in the final model and predicted means from the cross-validation was very high (Pearson's $r=0.87, P<0.001$ ), offering further support for the validity of this model.

This model was based on mean field measurements, and therefore, its accuracy depends on the representativeness of measured results. Predictions in this study would be high if the purpose of field monitoring was to identify overexposure issues or exposures in unusual conditions. Given that a majority of the reported results were sampled in open environments and various degrees of ventilation were well represented, it is likely that the welding processes and environments that are represented in this study are typically encountered by the study population for which these means will be used in estimating exposures. In addition, the mean Mn exposure across studies presented here $\left(0.27 \mathrm{mg} \mathrm{m}^{-3}\right)$ is virtually equal to mean $\mathrm{Mn}$ exposures from three separate welding databases presented by other authors (Flynn and Susi, 2010), indicating that Mn concentrations 
represented in this model are representative of typical field exposures. Furthermore, Mn content of welding fume is commonly $<5 \%$ (Harris, 2002), and the calculations from this model predict $\mathrm{Mn}$ to constitute $\sim 4 \%$ of total welding particulate. Finally, the predicted mean exposures calculated with the final model are reasonably within an expected range of exposures for both welding particulate and Mn exposures.

\section{CONCLUSIONS}

In summary, it was possible to develop and validate an exposure model for welding particulate and Mn means based on measurement data reported in the published literature. Improvements to this model may be made with more detailed descriptions and reporting of exposure determinants. The estimates of mean exposure developed from this model are not expected to be as accurate as historical individual exposure measurements of study participants; however, the relatively large amount of variance explained by the final model along with the positive generalizability results from the cross-validation increases the confidence that the estimates derived from this model can be used for estimating welder exposures in absence of individual measurement data.

\section{SUPPLEMENTARY DATA}

Supplementary data can be found at http://annhyg .oxfordjournals.org/

\section{FUNDING}

Michael J. Fox Foundation, National Institutes of Health grants (R01 ES013743, K24 ES017765, P42 ES04696); the Clinical Science Translational Award (NCRR UL1 RR024992); the Neuroscience Blueprint grant (NS057105); the American Parkinson Disease Association Advanced Research Center at Washington University; the Greater St Louis Chapter of the APDA.

\section{REFERENCES}

Aitchison J, Brown JAC. (1957) The lognormal distribution. London: Cambrigde University Press ISBN 9780521040112 .

ACGIH. (1992) Documentation of TLVs. Cincinnati, OH: American Conference of Governmental Industrial Hygienists. Antonini JM. (2003) Health effects of welding. Crit Rev Toxicol; 33: 61-103.

Boelter FW, Simmons CE, Berman L et al. (2009) Two-zone model application to breathing zone and area welding fume concentration data. J Occup Environ Hyg; 6: 298-306.

Bowler RM, Gysens S, Diamond E et al. (2006a) Mn exposure: neuropsychological and neurological symptoms and effects in welders. Neurotoxicology; 27: 315-26.

Bowler RM, Koller W, Schulz PE. (2006b) Parkinsonism due to manganism in a welder: neurological and neuropsychological sequelae. Neurotoxicology; 27: 327-32.

Bowler RM, Nakagawa S, Drezgic M et al. (2007) Sequelae of fume exposure in confined space welding: a neurological and neuropsychological case series. Neurotoxicology; 28: 298-311.

Burgess WA. (1995) Recognition of health hazards in industry: a review of materials processes. 2nd edn. New York: Wiley Interscience. ISBN 978-0471577164.

Chandra SV, Shukla GS, Srivastava RS et al. (1981) An exploratory study of Mn exposure to welders. Clin Toxicol; 18: 407-16.

Discalzi G, Pira E, Hernandez EH et al. (2000) Occupational Mn parkinsonism: magnetic resonance imaging and clinical patterns following $\mathrm{CaNa} 2$-EDTA chelation. Neurotoxicology; 21: 863-6.

Flynn MR, Susi P. (2010) Mn, iron, and total particulate exposures to welders. J Occup Environ Hyg; 7: 115-26.

Fored CM, Fryzek JP, Brandt L et al. (2006) Parkinson's disease and other basal ganglia or movement disorders in a large nationwide cohort of Swedish welders. Occup Environ Med; 63: 135-40.

Fryzek JP, Hansen J, Cohen S et al. (2005) A cohort study of Parkinson's disease and other neurodegenerative disorders in Danish welders. J Occup Environ Med; 47: 466-72.

Goller JW, Paik NW. (1985) A comparison of iron oxide fume inside and outside of welding helmets. Am Ind Hyg Assoc J; 46: 89-93.

Goutte C. (1997) A note on free lunches and cross-validation. Neural Comput; 9: 1211-5.

Harris MK. (2002) Welding health and safety. Fairfax, VA: AIHA Press.

Harris MK, Ewing WM, Longo W et al. (2005) Mn exposures during shielded metal arc welding (SMAW) in an enclosed space. J Occup Environ Hyg; 2: 375-82.

Hein MJ, Waters MA, van WE et al. (2008) Issues when modeling benzene, toluene, and xylene exposures using a literature database. J Occup Environ Hyg; 5: 36-47.

Hernandez EH, Discalzi G, Valentini C et al. (2006) Follow-up of patients affected by Mn-induced Parkinsonism after treatment with $\mathrm{CaNa}$ (2)EDTA. Neurotoxicology; 27: 333-9.

Hornung RW, Greife AL, Stayner LT et al. (1994) Statistical model for prediction of retrospective exposure to ethylene oxide in an occupational mortality study. Am J Ind Med; 25: $825-36$.

Howden DG, Desmeules MJA, Sracci R et al. (1988) Respiratory hazards of welding: occupational exposure characterization. Am Rev Respir Dis; 138: 1047-50.

IARC. (1990) IARC monographs on the evaluation of carcinogenic risks to humans: chromium, nickel, and welding. Vol 49. Lyons: IARC. ISBN 9789283212492.

Josephs KA, Ahlskog JE, Klos KJ et al. (2005) Neurologic manifestations in welders with pallidal MRI T1 hyperintensity. Neurology; 64: 2033-9.

Koller WC, Lyons KE. (2004) Effect of levodopa treatment for parkinsonism in welders: a double-blind study-reply. Neurology; 63: 1541.

Korczynski RE. (2000) Occupational health concerns in the welding industry. Appl Occup Environ Hyg; 15: 936-45. 
Liu D, Wong H, Quinlan P et al. (1995) Welding helmet airborne fume concentrations compared to personal breathing zone sampling. Am Ind Hyg Assoc J; 56: 280-3.

Meeker JD, Susi P, Flynn MR. (2007) Mn and welding fume exposure and control in construction. J Occup Environ Hyg; 4: 943-51.

Nelson K, Golnick J, Korn T et al. (1993) Mn encephalopathyutility of early magnetic-resonance-imaging. $\mathrm{Br} \mathrm{J}$ Ind Med; 50: 510-3.

Park RM. (2005) Potential occupational risks for neurodegenerative diseases. Am J Ind Med; 48: 63-77.

Racette BA, McGee-Minnich L, Moerlein SM et al. (2001) Welding-related parkinsonism—clinical features, treatment, and pathophysiology. Neurology; 56: 8-13.

Racette BA, Tabbal SD, Jennings D et al. (2005) Prevalence of parkinsonism and relationship to exposure in a large sample of Alabama welders. Neurology; 64: 230-5.

Sadek AH, Rauch R, Schulz PE. (2003) Parkinsonism due to manganism in a welder. Int J Toxicol; 22: 393-401.
Smargiassi A, Baldwin M, Savard S et al. (2000) Assessment of exposure to $\mathrm{Mn}$ in welding operations during the assembly of heavy excavation machinery accessories. Appl Occup Environ Hyg; 15: 746-50.

Stern RM, Berlin A, Fletcher A et al. (1986) International conference on health hazards and biological effects on welding fumes and gases. Summary report. Int Arch Occup Environ Health; 57: 237-46.

Susi P, Goldberg M, Barnes P et al. (2000) The use of a taskbased exposure assessment model (T-BEAM) for assessment of metal fume exposures during welding and thermal cutting. Appl Occup Environ Hyg; 15: 26-38.

Wallace M, Shulman S, Sheehy J. (2001) Comparing exposure levels by type of welding operation and evaluating the effectiveness of fume extraction guns. Appl Occup Environ Hyg; 16: 771-9.

Yoon CS, Paik NW, Kim JH. (2003) Fume generation and content of total chromium and hexavalent chromium in fluxcored arc welding. Ann Occup Hyg; 47: 671-80. 